\title{
Relación familia-escola: caso concreto do alumnado con Dificultades de Aprendizaje
}

\author{
Family- School relationship: the family of the students with learning disabilities
}

\author{
Ana Parada-Gañete \\ Dpto. Didáctica y Organización Escolar, Facultad de Ciencias de la Educación, Universidad de Santiago de Compostela.
}

\begin{abstract}
Resumen
O proxecto de tese que presentamos versa sobre a relación entre a familia e a escola. Concretamente ten como obxectivo xeral coñecer, explicar a comprender a natureza da relación familia-escola do alumnado con Dificultades de Aprendizaxe, para identificar as súas posibles eivas, explicar a súa xénese e comprender as actuacións dos directamente implicados. Mediante unha investigación descritiva e interpretativa intentaremos coñecer as percepcións da familia e da escola sobre a relación que manteñen, a explicación que dan ambos axentes ás dificultades de aprendizaxe do alumnado e cales son as medidas que poñen en marcha para atender as necesidades dos mesmos.

Palabras clave: relación familia-escola, dificultades de aprendizaxe, cooperación e colaboración familia-escola.
\end{abstract}

\begin{abstract}
The research project that we present below is about relationship the family and the school. Specifically has a main objectives the know, explain and understand the nature of the family-school relationship to the students with learning disabilities, as well as identify the problems and defects this relation, explain his origin, comprise the performances of the directly involved. Through a descriptive and interpretative research we will try to learn and understand the perceptions of family and school about their relationship, to the explanation that both actors give to learning disabilities of the students and what are the measures that family and school set in motion to cater for the needs of them.

Keywords: family school relationship, family school partnership, learning disabilities.
\end{abstract}

A educación dos nenos estase a converter, cada vez máis, nun proceso complexo e cheo de interrogantes no que se ven implicados non só profesionais do eido educativo, senón tamén toda a sociedade en xeral e máis concretamente a comunidade que rodea aos nenos en idade de escolarización. A participación na educación de todos os actores que interveñen no proceso de ensino e de aprendizaxe do alumnado, ademais de ser un dereito constitúe unha necesidade, para lograr que a educación se converta nun proxecto común para o desenvolvemento do suxeito e, como consecuencia, para o desenvolvemento da sociedade.

Esta comunicación ten como obxectivo dar conta do proxecto de Tese de Doutoramento que estamos a desenvolver no Departamento de Didáctica e Organización Escolar da Facultade de Ciencias da Educación da Universidade de Santiago de Compostela, que versa sobre A relación familia - escola: o caso concreto de familias de alumnado con Dificultades de Aprendizaxe.

Tradicionalmente, tense traballado moito sobre o tema da participación das familias na escola e sobre a educación inclusiva dos nenos diagnosticados con algún tipo de discapacidade. O propósito desta tese de doutoramento é apoiarnos en ditas investigacións para intentar coñecer e describir a relación entre a familia e a escola daquel alumnado que, sen estar diagnosticado con ningunha discapacidade, presenta dificultades de aprendizaxe que lle impiden un desenvolvemento ordinario do seu proceso de aprendizaxe.

Deste xeito, o tema xustifícase pola singularidade que ten o proceso de escolarización do alumnado con Dificultades de Aprendizaxe, o cal se atopa nunha situación de risco e de vulnerabilidade na que non é quen de seguir o ritmo dos seus iguais no proceso de ensinanza-aprendizaxe e podería acabar nunha situación de fracaso escolar. Neste contexto, xorde a necesidade de que as familias e a escola se coordinen para mellor atender as dificultados de dito alumnado no seu proceso de escolarización

Así, a selección deste tema en concreto responde a unha inquedanza por indagar nas peculiaridades da relación entre a familia e a escola do alumnado con Dificultades de Aprendizaxe, á necesidades de coñecer as posibles diferenzas entre a implicación das familias con fillos/as que presentan Dificultades de Aprendizaxe e das familias de nenos/as que non as teñen, e a implicación persoal e profesional coa educación inclusiva e co dereito de outorgar a todos os nenos/as por igual unha educación de calidade.

A nosa investigación pretende constituírse con unha estrutura clásica formada por dous grande bloques:

- Marco Teórico: construído arredor de categorías de análise respecto da relación familia-escola e das dificultades de aprendizaxe.

- Marco Empírico: que contará tamén con unha estrutura clásica onde se describirá as características e os resultados do estudo de campo levado a cabo na investigación.

A continuación presentamos os apartados comúns aos proxectos de Tese de Doutoramento para que quede máis claro cáles son as características da investigación que temos iniciado: o contexto da investigación, os obxectivos, a mostra, a metodoloxía e a previsión de resultados. 


\section{$O$ contexto da investigación}

Un dos retos máis importantes aos que se enfrontan os Sistemas Educativos hoxe en día é o de ofrecer unha resposta educativa de calidade a todo o alumnado sen exclusións (Calvo, Haya e Susinos, 2012), para poder dar resposta ao dereito que teñen todos os cidadáns a unha educación que teña como obxectivo o pleno desenvolvemento da personalidade humana, principio recollido no artigo 26 da Declaración Universal dos Dereitos Humanos. Isto supón asumir o compromiso de loitar por unha Educación Inclusiva que converta a escola nunha espazo que acolla a todos: alumnado, familia e profesionais docentes.

A Educación Inclusiva constitúe un chamamento para o recoñecemento e o respecto á diversidade humana co fin de aprender dela, para ser mellores persoas e profesionais. (Simón, C. \& Echeita, G., 2012, p.32). A inclusión educativa implica reducir a exclusión, a discriminación, as barreiras para o aprendizaxe e a participación, reestruturar as culturas, políticas e prácticas dos centros para responder á diversidade e tratar a todos por igual (Booth y Ainscow, 2011) e ten como ambiciosa expectativa a de conseguir a necesaria alianza que debe construírse entre todas as familias e o profesorado (Simón, C. y Echeita, G., 2012, p.32).

$\mathrm{Na}$ educación dos nenos/as e dos adolescentes entran en xogo múltiples influencias que proveñen de diferentes contextos. Algúns deles son especialmente evidentes e teñen unha clara e explícita intencionalidade educativa, como son a familia e a escola (Simón, C., Echeita, G., 2012, p.31).

Creemos que é fundamental constituír Redes de Colaboración dentro das escolar e entre estas e a comunidades para conseguir plenamente unha Educación Inclusiva (Ainscow, 2011; Ainscow e West, 2008), xa que a capacidade dun entorno como a familia e a escola para funcionar de maneira eficaz como contexto de desenvolvemento depende da existencia e natureza das interconexións sociais entre os contextos (Simón, C., Echeita, G., 2012, p.31). Asumir unha perspectiva comunitaria en Educación é unha das claves importantes para o cambio educativo, é a maneira en que profesionais e axentes implicados en cada institución educativa (asesores, profesores de apoio interno, titores, equipo directivo, alumnos, familia) aprendan e traballen xuntos para solucionar as dificultades que xorden no seu contexto educativo e social ( Gallego, C, 2011, p.94).

Reafirmando este parecer, Simón, C, e Echeita, G (2012) sosteñen:

O potencial evolutivo dos distintos microsistemas, como son a familia e a escola, aumenta cando son capaces de traballar xuntos para lograr obxectivos comúns relacionados cos nenos e nenas e, polo tanto, de emprender actividades que estimulen a confianza mutua, con unha orientación positiva, nas que se logren consensos e metas compartidas. Este "espazo" que crean e que variará en función da calidade e cualidade das relacións que se establezan, exerce unha notable influencia, non sempre suficientemente valorada (máis alá do politicamente correcto ao dicir que "a relación familia e escola é importante), no desenvolvemento e a educación dos nenos e dos adolescentes. Incluso unha aparente "ausencia de relación" ou unha relación negativa entre ambos contextos (falta de entendemento, de comunicación, de pautas de actuación coherentes, relacións lineais e xerárquicas, enfrontamentos, etc.), crea un espazo concreto que inflúe dunha determinada maneira nos axentes que o protagonizan. Así, por exemplo, pode converterse nun factor de risco ou de protección para as familias en xeral e para os nenos en particular, ou ser unha fonte de estres ou satisfacción profesional para o docente (Simón, C., Echeíta, G., 2012, pag. 32).

Na frase citada queda xustificada á importancia dos procesos de relación entre a familia a escola para o desenvolvemento integral dos individuos. Ademais, é importante recordar tamén que para conseguir unha Educación Inclusiva que pase por unha óptima relación entre a familia e a escola é necesario "escoitar as voces de todos os membros da comunidade educativa" (Simón, C., Echeita, G., 2012, pag 33). En definitiva nunha sociedade democrática a educación escolar ou é inclusiva ou non é educación.

\section{Obxecto de Estudo}

O obxecto de estudo da investigación é pois a relación entre as familias e a escola do alumnado con Dificultades de Aprendizaxe que, como tal, non constitúe unicamente un tema, senón máis ben, un problema educativo que afecta ás relacións que manteñen entre si milleiros de persoas envolvidas nos procesos de escolarización. A necesidade dunha boa comunicación entre elas, que asegure a imprescindible colaboración que se require para desenvolver un proxecto educativo que ou é compartido ou non é educativo, revelase como unha tarefa constantemente pendente para cada nova xeración.

Entender a importancia desta cooperación implica situarnos nunha posición na que a familia adquire un rol de "socio" (partner) e distánciase dunha posición de axente alleo ao centro escolar, o que supón, en consecuencia, ver as familias como un recurso para o propio centro e de forma particular para o docente. Ademais, é certo que as familias deberían asumir unha posición paralela como corresponsables da educación dos seus fillos (valorar ao docente, recoñecer a importancia da escola, apoiar e implicarse na mesma) e non actuar como meros "receptores pasivos dun servizo", ao que simplemente esixen unha determinada "rendición de contas" ( Simón, C. y Echeita, G., 2012, pag 33).

A idea é, polo tanto, unha cambio de actitude por parte de ambos axentes, familia e escola, co obxectivo de outorgar máis e mellores posibilidades ao alumnado en xeral e, ao alumnado con Dificultades de Aprendizaxe en particular. 


\section{As preguntas de investigación}

A tese de doutoramento parte dunha serie de supostos de partida que se concretan nunha cuestión central: cómo se configura na actualidade a relación entre a familia e a escola do alumnado con Dificultades de Aprendizaxe que presenta fracaso escolar? E, este interrogante central, permítenos establecer tres cuestións máis específicas: existen diferenzas entre a participación na escola das familias de suxeitos con Dificultades de Aprendizaxe e das familias de suxeitos con un desenvolvemento ordinario do seu proceso de aprendizaxe?, poderíamos encontrar diferenzas entre o tipo de relación que manteñen coa escola as familias de nenos con Dificultade de Aprendizaxe e as familias de nenos con un desenvolvemento ordinario?, cómo afecta o tipo de relación entre a familia e a escola ao desenvolvemento óptimo do alumnado, concretamente do alumnado con Dificultades de Aprendizaxe?

Deste xeito, os supostos de partida cos que contamos son:

- En relación ao primeiro interrogante, poderíamos dicir que o suposto sería que si existen diferenzas entre a colaboración das familias do alumnado desenvolvemento académico ordinario e a das familias do alumnado con Dificultades de Aprendizaxe, sendo maior a colaboración destas últimas.

- En relación ao segundo interrogante, o suposto que manexamos sería que si existen diferentes tipos de relación entre un e outro grupo de familias coa escola e tamén entre a escola e un e outro grupo de familias. Neste sentido, habería que confrontalas co obxecto de extraer modelos de actuación a partir da relación entre a familia do alumnado con Dificultades de Aprendizaxe coa escola.

- En relación ao terceiro interrogante, o suposto sería que unha boa práctica de colaboración e coordinación entre as familias e a escola favorece o desenvolvemento óptimo de calquera tipo de alumnado e máis se este presenta fracaso escolar ou se atopa nunha situación de vulnerabilidade.

\section{Obxectivo}

En relación cos aspectos que se desexa investigar e coñecer na presente investigación, especificamos a continuación o noso obxectivo xeral que se concreta en sete obxectivos específicos que decidimos clasificar en función dos dous grandes bloques dos que constará a tese de doutoramento: obxectivos específicos do marco teórico e obxectivos específicos do marco empírico.

\section{Obxectivo xeral}

- Coñecer, explicar e comprender a natureza das relacións familia-escola do alumando con necesidades específicas de apoio educativo (NEAE).

\section{Obxectivos Específicos}

- Sistematizar o coñecemento existente sobre as relacións entre a familia e a escola
- Analizar os diferentes modelos teóricos conceptuais e as diversas prescricións lexislativas ao respecto

- Describir e explicar as peculiaridades desa relación no caso das familias con fillos con Necesidades Específicas de Apoio Educativo (NEAE).

- Identificar as principais eivas desa relación en correspondencia coas alternativas de solución existentes.

- Describir e analizar as relacións entre as familias con fillos con Necesidades Específicas de Apoio Educativo (NEAE) e a escola, nunha mostra representativa dos Centros Educativos da Comunidade Autónoma de Galicia.

- Coñecer, contrastar, valorar e triangular as percepcións que os membros máis directamente implicados das familias e da escola manteñen sobre a natureza da súas relacións.

- Desenvolver un estudo de caso sobre a relación familia - escola no canto do alumnado con Necesidades Específicas de Apoio Educativo (NEAE).

\section{Mostra}

A mostra da tese de doutoramento sairá de todos os CEIP (Colexios de Educación Infantil e Primaria) e os CEP (Colexio de Educación Primaria) da Comunidade Autónoma de Galicia, configurando deste xeito o universo de estudo da nosa investigación. Por outra banda, a nosa poboación de referencia estará constituída por unha selección deses Centros Educativos e, por último, a nosa mostra produtora de datos serán por un lado, os pais e nais de nenos con Necesidades Específicas de Apoio Educativo que están escolarizados en ditos Centros Educativos e, por outro lado, os profesores máis directamente implicados na docencia a eses alumnos.

\section{A nosa investigación sitúase no Paradigma} Interpretativo da Investigación Educativa xa que ademais de describir a realidade obxecto de estudo pretende interpretar e comprender esa realidade, a través da análise das percepcións das persoas implicadas e que desvelan os significados que manexan. A metodoloxía será mixta, tanto cuantitativa como cualitativa, e combinará un cuestionario sobre percepcións para o grupo grande de referencia, con entrevistas a un grupo de pais e de profesores, ademais dun estudo de caso mediante unha observación participante. Referencias

O proceso de realización do proxecto de investigación divídese en catro fases de recollida e análise da información. Unha primeira fase de revisión documental que da inicio ao estudo de campo e que permanece aberto durante todo o proceso, enriquecéndose e retroalimentándose das fases empíricas da investigación. Mergullándonos no que é o marco empírico da tese de doutoramento, teríamos unha segunda fase de construción e planificación das técnicas e instrumentos de recollida de información, que ten como obxectivo deseñar recursos que mellor nos axuden a pescudar toda a información necesaria para a nosa investigación. Unha terceira fase de estudo de campo propiamente dito, 
entendido como o traballo directo e persoal que realiza o investigador cos informantes claves da investigación. $\mathrm{E}$, por último, unha cuarta fase de análise e interpretación da información recollida.

\section{Previsión de resultados}

En relación á previsión de resultados da nosa investigación esperamos encontrar que as familias do alumnado con Necesidades Específicas de Apoio Educativo están máis implicadas na escolarización dos seus fillos.

Sendo así, como esta implicación é por definición desexable para facer efectiva a colaboración entre a familia e a escola, o que pretendemos con este proxecto de investigación é aprender da experiencia (dos valores, actitudes e condutas) que desenvolven esas familias para, non soamente sistematizar orientacións precisas en orde a fundamentar a relación entre este tipo peculiar de familias coa escola e viceversa, senón para estendelas con carácter xeral ao conxunto de familias con fillos escolarizados.

En definitiva, esperamos atopar evidencias de boas prácticas educativas no canto das relacións entre a familia e a escola, sendo estas as que se levan a cabo entre as familias de alumnos máis vulnerables, para poder explicar e describir modelos de actuacións ao alcance de toda a comunidade educativa que favorezan a relación familia-escola e, como consecuencia, a escola inclusiva e o desenvolvemento integral dos individuos.

\section{Referencias}

Ainscow, M.; Booth, T. \& Dyson, A. (2006). Improving schools, developing inclusión. London: Routledge.

Booth, T. \& Ainscow, M. (2011). Index for inclusion: developing learning and participation in schools $\left(3^{\mathrm{a}}\right.$ ed.). Bristol: Centre for Studies on Inclusive Education (CSIE).

Casanova, M.A. (2011). Educación inclusiva: un modelo de futuro. Madrid: Wolters Kluwe.

Gallego, C. (2011). El apoyo inclusiva desde la perspectiva comunitaria. Revista Interuniversitaria de Formación de Profesorado, 25 (1), pp. 93-109.

Monarca, H.A. (2013). Trabajo colaborativo con padres y madres. Ámbito de actuación desde la Orientación Educativa. Revista Española de Orientación y Psicopedagogía, 24 (3), pp. 114-123.

Sandín Esteban, M.P. (2003). Investigación Cualitativa en Educación. Fundamentos y Tradiciones. Madrid: McGrawHill.

Simón, C. \& Echeita, G. (2012). La alianza entre las familias y la escuela en la educación del alumnado más vulnerable. Padres y Maestros, 344, pp. 31-34.

Almirall, R. (2011). Abordando la relación familia-escuela desde una perpectiva colaborativa. Orientación educativa: Modelos $y$ estrategias de intervención (pp. 91-108) Ministerio de Educación, Secretaría General Técnica: Graó.

Barca Lozano, A. (2009). Equidad e inclusión educativa: Hacia una interacción con los procesos motivacionales y el aprendizaje. Políticas educativas y compromiso social: El progreso de la equidad y la calidad (pp. 105-122) Octaedro Editorial.
Bolívar Botía, A. (2006). Familia y escuela: Dos mundos llamados a trabajar en común. Revista De Educación, (339), pp. 119-146.

Bolívar Botía, A. (2007). La participación de las familias: Nuevas percepciones y realidades. Participación Educativa, (4), pp. 60-64.

Comellas, M. J. (2009). Familia y escuela: Compartir la educación. Barcelona : Graó.

Domínguez Pérez, M. T. (2009). A participación das familias nos centros educativos como estratexia para a mellora dos programas de intervención do alumnado con N.E.A.E. Quinesia: Revista De Educación Especial, (42), pp. 43-48.

Dowling, E. (2010). Una aproximación sistemática a la relación entre familias y escuelas. Nuevos paradigmas para un tiempo nuevo. Elche: Ajuntament d'Elx, Regidoria d'Educació i Festes.

Escudero Muñoz, J. M. \& Bolívar Botía, A. (2008). Alumnos en riesgo de exclusión educativa y buenas prácticas: Dos conceptos borrosos para comprender fenómenos educativos complejos. Organizaciones educativas al servicio de la sociedad. España: Wolters Kluwer.

Gairín Sallán, J. (2007). La construcción de una escuela para todos y todas. Coeducación y prevención temprana de la violencia de género (pp. 23-59) Ministerio de Educación, Secretaría General Técnica.

García Benítez, A. (2010). Sociedad, familia y educación: desde una aproximación sociológica. Sevilla: Padilla Libros.

García Sanz, M. P., Gomariz Vicente, M. A., Hernández Prados, M. A. \& Parra Martínez, J. (2010). La comunicación entre la familia y el centro educativo, desde la percepción de los padres y madres de los alumnos. Educatio Siglo XXI: Revista De La Facultad De Educación, (28), pp. 157-188.

López Larrosa, S., \& Dubra, M. (2010). Las relaciones familia-escuela desde la perspectiva de los adolescentes. Revista Galego-Portuguesa De Psicoloxía e Educación: Revista De Estudios e Investigación En Psicología y Educación, (18), pp. 181-188.

Marchesi Ullastres, A. (2005). Fracaso escolar y cambio educativo. Educación, igualdad y diversidad cultural (pp. 87-102) Biblioteca Nueva.

Muñoz Moreno, J. L., Rodríguez Gómez, D., \& Barrera Corominas, A. (2013). Herramientas para la mejora de las organizaciones educativas y su relación con el entorno. Perspectiva Educacional, 52(1), pp. 97-123.

Parellada Enrich, C. (2008). Familia y escuela ¿se invaden, se necesitan...? Cuadernos De Pedagogía, (378), pp. 46-51.

Parrilla Latas, M. A. (2004). La voz de la experiencia: La colaboración como estrategia de inclusión. La escuela inclusiva: Prácticas y reflexiones (pp. 37-46) Editorial Laboratorio Educativo.

San Fabián Maroto, J. L. (2006). Participación de las familias y acción tutorial: Dos puertas para el cambio. Participación de las familias en la vida escolar: Acciones y estrategias (pp. 131-148) Ministerio de Educación y Ciencia. 